Journal of Bangladesh Academy of Sciences, Vol. 39, No. 1, 45-51, 2015

\title{
PHYSIOLOGICAL ANALYSIS OF GROWTH AND YIELD OF POTATO IN RELATION TO PLANTING DATE
}

\author{
FARIDA BEGUM* ${ }^{*}$, B.C. KUNDU AND M. I. HOSSAIN \\ Tuber Crops Research Centre, Bangladesh Agricultural Research Institute, Joydebpur, \\ Gazipur-1701, Bangladesh
}

\begin{abstract}
Experiments on planting date on growth and yield of potato revealed that planting date had a significant effect on plant height, crop growth and yield. Higher leaf area index (LAI) was observed in case of optimum sowing date (16 Nov.) which resulted in higher total dry matter (TDM) production and ultimately gave higher yield. Delayed planting gave lower LAI, lower TDM and had adverse effect on tuber yield. No significant variation was observed in tuber yield due to interaction effect of variety and planting date.
\end{abstract}

Key words: Physiological analysis, Potato, Date of planting, Growth, Yield

\section{INTRODUCTION}

Potato is the fourth major food crop of the world next to rice, wheat and maize and third important crop in Bangladesh (Rashid 1995). Compared to all other cultivated crops in Bangladesh, potato gave the highest yield per unit area and time. In Bangladesh, the optimum time of sowing of potato is the second week of November, but in many cases the potato crops are planted under late sown condition due to delayed harvesting of transplanted aman. Delayed planting reduced the yield of potato. The physiological causes that led to yield reduction in delayed planting of potato had not been reported from Bangladesh. Therefore, an attempt was made to analyze the growth and yield of potato in relation to planting date.

\section{MATERIALS AND METHOD}

The field experiment was carried out at Tuber Crops Research Centre (TCRC), Bangladesh Agricultural Research Institute, Joydebpur, Gazipur during cropping season of 2010 - 2011. The cultivars Asterix and Diamant were included in this study. A randomized complete block design was used with three replications. The unit plot size was $3.0 \mathrm{~m} / 4.2 \mathrm{~m}$. The row to row distance was $60 \mathrm{~cm}$ and plant to plant distance was 25 $\mathrm{cm}$. giving a population of 12 plants per line. Fertilizer NPKS was applied as per

\footnotetext{
* Corresponding author.
} 
recommendation of TCRC (urea- 350, MP-220, TSP- 250 and gypsum $120 \mathrm{~kg} / \mathrm{ha}$ and cow dung $10 \mathrm{t} / \mathrm{ha}$ ). Urea was given in split application with $1 / 2 \mathrm{~N}$ as basal dose and $1 / 2$ at the time of earthing up. The treatments consisted of four dates of planting viz. $01 \mathrm{Nov}$., 16 Nov, 01 Dec. and 16 Dec. of 2010. Three plants from each replication were harvested randomly at 15 days interval. Different parts of plant were separated and dried in an oven at $80^{\circ} \mathrm{C}$ for 72 hours and the dry weights were taken. Leaf area, NAR, CGR, RGR (Radford 1967) and chlorophyll contents (Witham et al. 1971) were measured. Yield and yield components were also recorded.

\section{RESULTS AND DISCUSSIONS}

There was a progressive delay in 50\% emergence with delayed planting. Emergence delay varied from 11 to 18 days. The 50\% emergence occurred at 11, 14, 16 and 18 days after planting at $\mathrm{D}_{1}$ (1 Nov. sowing), $\mathrm{D}_{2}\left(16\right.$ Nov. sowing), $\mathrm{D}_{3}$ (1 Dec. sowing) and $\mathrm{D}_{4}$ (16 Dec. sowing), respectively (Table 1). Delayed planting caused reduction in crop duration, plant height, leaf number and also leaf area. Plant height increased with time and it became reduced at harvesting stage.

Table 1. Influence of sowing time on yield and yield components of potato.

\begin{tabular}{lcccccc}
\hline Sowing time & $\begin{array}{c}\text { Crop } \\
\text { duration (days) }\end{array}$ & $\begin{array}{c}\text { Plant height } \\
(\mathrm{cm})\end{array}$ & $\begin{array}{c}\text { No. of } \\
\text { stem/plant }\end{array}$ & $\begin{array}{c}\text { No. of } \\
\text { tuber/plant }\end{array}$ & $\begin{array}{c}\text { Yield/ } \\
\text { plant }(\mathrm{kg})\end{array}$ & $\begin{array}{c}\text { Yield } \\
(\mathrm{t} / \mathrm{ha})\end{array}$ \\
\hline 01 Nov (D1) & 90 & $54.67 \mathrm{~b}$ & $3.39 \mathrm{~b}$ & $7.58 \mathrm{~b}$ & $9.43 \mathrm{ab}$ & $18.81 \mathrm{ab}$ \\
16 Nov. (D2) & 90 & $61.00 \mathrm{a}$ & $3.33 \mathrm{~b}$ & $11.60 \mathrm{a}$ & $11.13 \mathrm{a}$ & $21.23 \mathrm{a}$ \\
01 Dec. (D3) & 82 & $45.83 \mathrm{c}$ & $5.67 \mathrm{a}$ & $6.95 \mathrm{~b}$ & $8.92 \mathrm{~b}$ & $16.20 \mathrm{~b}$ \\
16 Dec. (D4) & 74 & $42.83 \mathrm{c}$ & $3.83 \mathrm{~b}$ & $7.92 \mathrm{~b}$ & $6.11 \mathrm{c}$ & $11.30 \mathrm{c}$ \\
CV (\%) & - & 9.73 & 27.69 & 20.75 & 14.65 & 12.62 \\
Variety & & & & & & \\
Asterix & & $54.50 \mathrm{a}$ & $4.64 \mathrm{a}$ & 8.72 & 8.86 & 16.98 \\
Diamant & & $47.67 \mathrm{~b}$ & $3.47 \mathrm{~b}$ & 8.31 & 8.93 & 16.79 \\
CV (\%) & 9.73 & 27.69 & 20.75 & 14.65 & 12.62 \\
\hline
\end{tabular}

Means followed by the same letter in a vertical column do not differ significantly at the $5 \%$ level.

Potato plants took 90 days to harvest when planted on 1 - 16 November, whereas duration reduced to 74 days when planted on 16 December. This is because high temperature decreases the growth duration. It was also observed that late sowing in potato increased the heat sum requirement by the cultivars. Because of shorter duration, phenological stages rapidly advanced due to availability of higher thermal units over a short period of time (Bishnoi and Taneja 1990). This might have resulted in force maturity. 
There was an initial increase of leaf number, reaching a maximum followed by a reduction. For early planting the life cycle was long and the number of leaves was the maximum after 65 days after planting (DAP) and then decreased. For late planting the life cycle of potato plant was short and the maximum number of leaves was found after 50 days and then decreased (Fig. 1a, b).

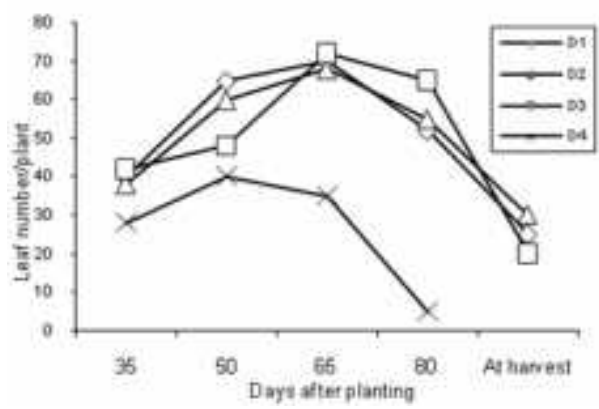

Fig. 1a. Effect of date of planting on leaf number of potato var. Asterix.

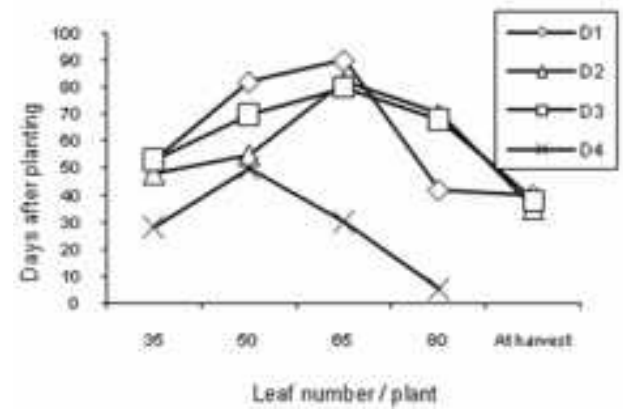

Fig. 1 b. Effect of date of planting on leaf number of potato var. Diamant.

Leaf area is one of the best measures of crop capacity to produce dry matter as dry matter production was found to be positively correlated with leaf area per plant (Sushant et al 1999). Leaf area increased up to 50 days after planting then declined in potato (Fig. $2 \mathrm{a}, \mathrm{b})$. Highest leaf area was observed in Diamant when planting time was 16 Nov. It was observed that 16 Nov. planting (D2) had the highest leaf area than other planting dates and thereby intercepted more incoming solar radiation and produced highest dry matter.

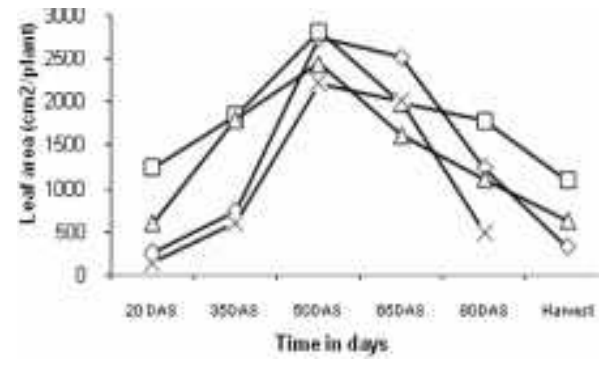

Fig. 2a. Effect of date of sowing on leaf area of potato var. Asterix.

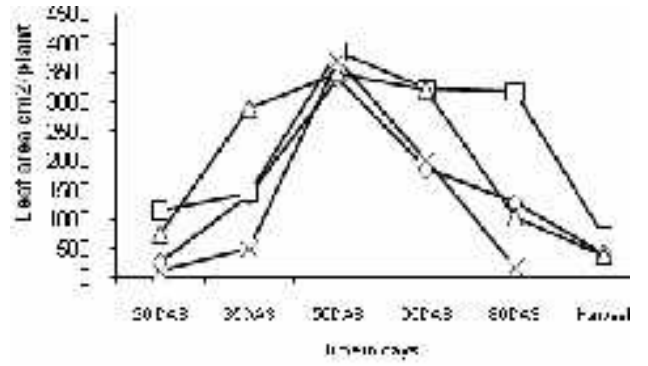

Fig. 2b. Effect of date of sowing on leaf area of potato var. Diamant.

Leaf area index (LAI) varied among the varieties under different sowing time (Fig. $3 \mathrm{a}, \mathrm{b})$. LAI increased up to $50 \mathrm{DAP}$ and then declined in both the varieties planted at different times. At 16 November planting, LAI of Diamant showed higher value than that of Asterix. Differences in LAI among these two varieties at different growth stages were due to cumulative effects of number of green leaves/plant. Delayed planting resulted in lower LAI. TDM production was proportional to LAI, as higher LAI resulted in higher TDM production. 


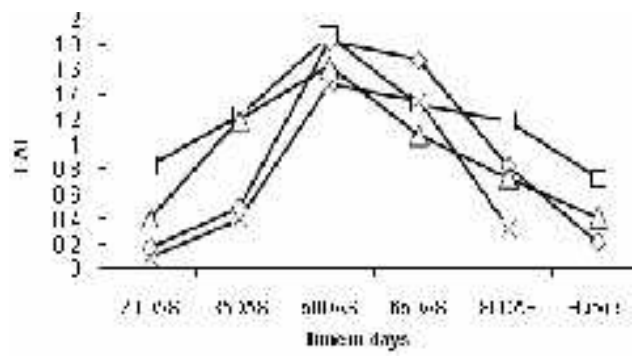

Fig. 3a. Effect of date of sowing on LAI of potato var. Asterix.

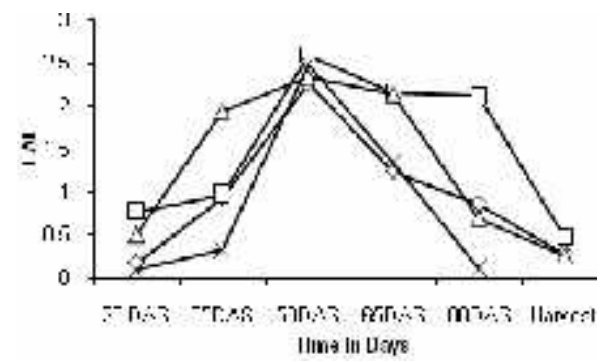

Fig. 3b. Effect of date of sowing on LAI of potato var. Diamant.

The NAR showed a declining trend as the crop advanced in age (Fig. 4a, b). The decrease in NAR with advancement of time might be due to shedding of leaves resulting in lower photosynthetic efficiency (Imai et al. 1993). The slight increase in NAR at 50 DAP may be due to higher CGR at this stage (Ferdous et al. 2004).

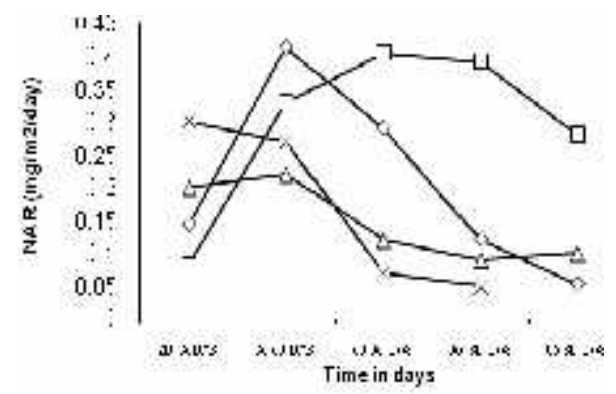

Fig. 4a. Effect of date of sowing on NAR of potato var. Asterix.

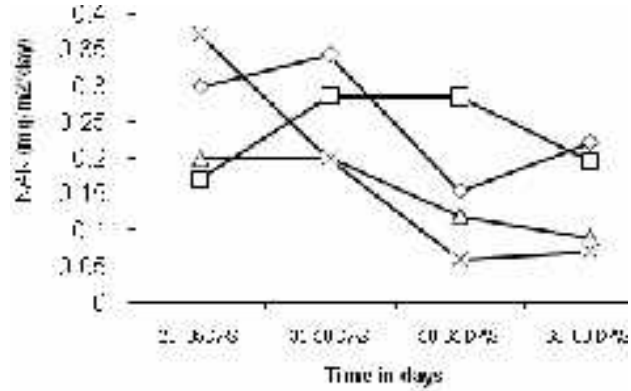

Fig. 4b. Effect of date of sowing on NAR of potato var. Diamant.

Relative growth rate (RGR) was higher at the early stages of crop growth and showed a decreasing trend as the crop advanced in age (Fig. 5a, b). The decrease in RGR was also due to decrease in NAR. Rao and Mitra (1988) reported a decrease in RGR due to decrease in NAR in ground nut.

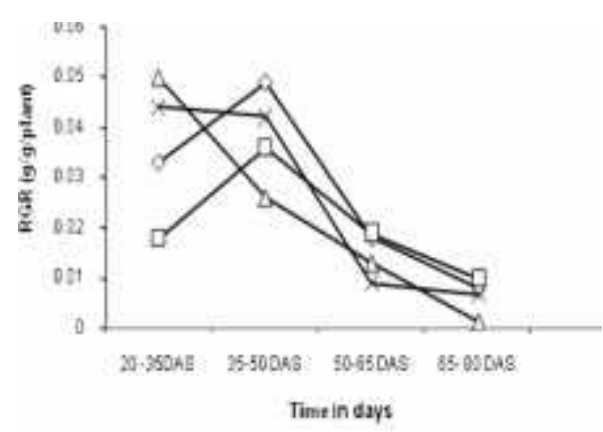

Fig. 5a. Effect of date of sowing on RGR of potato var. Asterix.

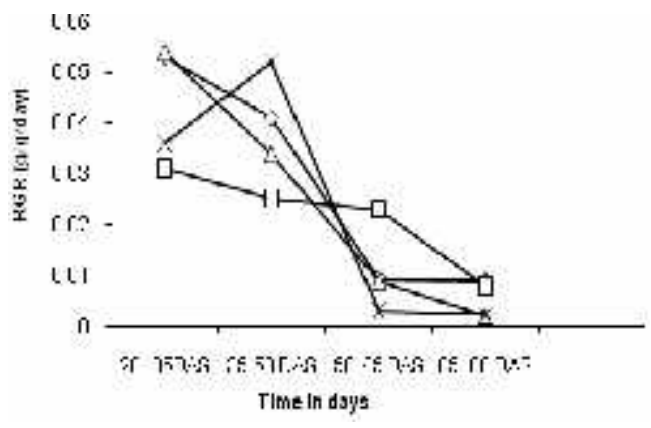

Fig. 5b. Effect of date of sowing on RGR of potato var. Diamant. 
Crop growth rate (CGR) increased up to 70 DAP and then declined (Fig. 6a, b). The differences in tuber yield in different treatment could be related to difference in CGR. The maximum CGR was observed between 60 and 70 days. Delayed planting decreased CGR.

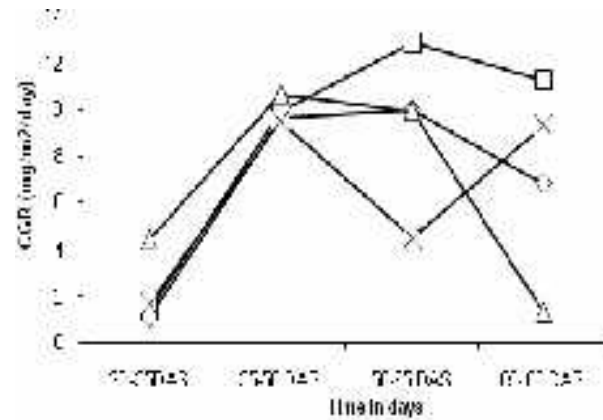

Fig. 6a. Effect of date of sowing on CGR of potato var. Asterix.

In Figs 1 to 6 the symbol $\diamond$ stands for $\mathrm{D}_{1}\left(1^{\text {st }}\right.$ November $) ; \Delta$ stands for $\mathrm{D}_{2}\left(16^{\text {th }}\right.$ November $)$; $\square$ stands for $\mathrm{D}_{3}\left(1^{\text {st }}\right.$ December $)$ and $\mathrm{x}$ stands for $\mathrm{D}_{4}\left(16^{\text {th }}\right.$ December $)$.

Light and temperature during growth period are more influential on chlorophyll content. Total chlorophyll content was higher in the initial stage and then decreased. Similar trend of chlorophyll content is also observed in Mungbean (Datta and Lahiri 1993). The decrease in total chlorophyll at the later stage might be attributed to leaf ageing. Chlorophyll content was found higher in Asterix than that of Diamant (Fig. 7a, b)

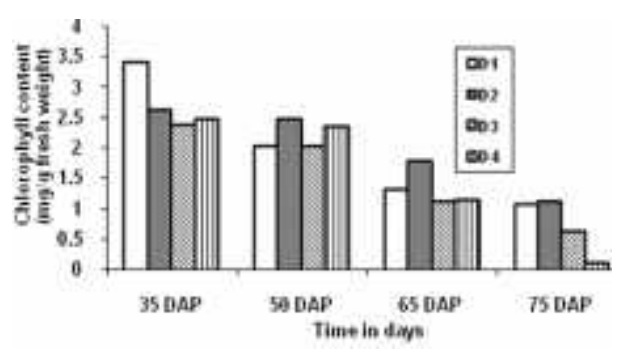

Fig. 7a. Chlorophyll content of potato (var. Asterix) at different stages of growth.

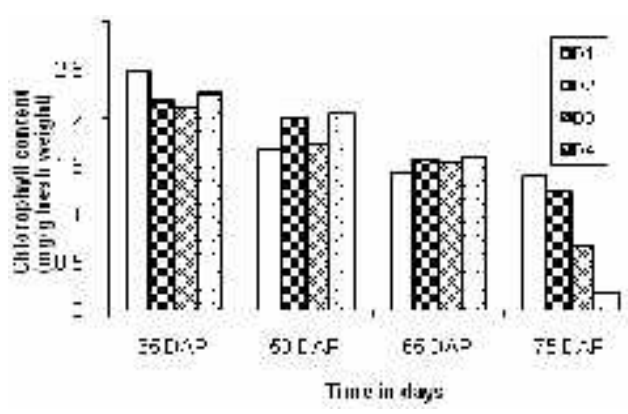

Fig. 7b. Chlorophyll content of potato (var. Diamant) at different stages of growth.

Total dry matter (TDM) content increased gradually with the progression of growth stages. At earlier stages, most of the dry matter was in leaf and stem (Fig. 8a, b) and from tuber initiation to tuber development it accumulated in stolon. At maturity stage and onwards stem and leaf dry weight decreased and this decrease could be due to translocation of assimilates from leaf and stem to tuber. The TDM production in Diamant was found greater than that of Asterix up to 80 DAP in all the planting dates. 


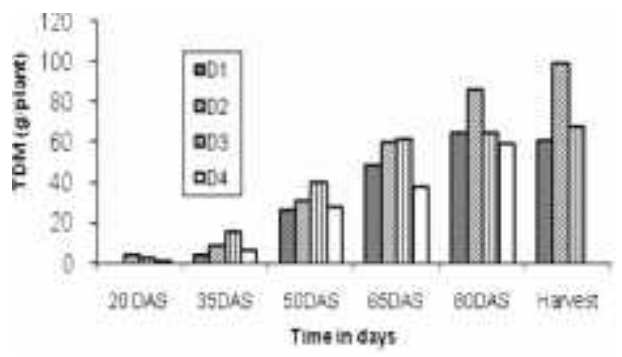

Fig. 8a. Chlorophyll content of potato (var. Asterix) at different stages of growth.

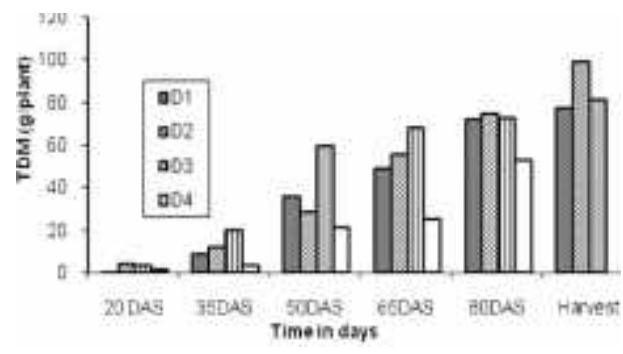

Fig. 8b. Chlorophyll content of potato (var. Diamant) at different stages of growth.

The sowing time significantly influenced yield and yield component of potato (Table 1). In the present work, the plant height was affected by delay planting. Date of planting had significant effect on plant height of both the varieties of potato. Maximum plant height was observed in 16 November sowing in Diamant (Table 1). Plant height of December 1 sowing and December 16 sowing was similar and significantly lower than the other two sowings. Highest number of tuber per plant was recorded from Nov. 16 sowing and was significantly higher than those of other three sowings. The highest yield ( $\mathrm{t} / \mathrm{ha}$ ) was recorded from Nov. 16 sowing which was closely followed and was statistically similar to that of November 1 sowing. December 16 sowing gave significantly low yield. The tuber number was maximum in 16 November sowing and significantly more than those of other sowings (Table 1).

From the results obtained it may be concluded that delayed planting had adverse effect on LAI resulting in lower TDM and ultimately reduced yield. Reduced leaf growth results in smaller canopy and produce smaller tuber. The physiological mechanisms giving rise to the ultimate yield is rather complex. There is a synchronization of different aspect of growth by the adjustment of the plant's internal biological clock and the external clock, represented by the season. Due to difference of plantation time there was synchronization of the internal and external clock, which affect physiological process in plants and ultimately on yield of potato.

\section{REFERENCES}

Bisnoi, O.P. and K.D. Tanejqa. 1990. Thermal requirement and yield of late sown wheat varieties at Hissar. J. Res. Haryana Agric. Univ. 20: 69-73.

Datta, R.K. and B.P. Lahiri, 1993. Nitrate reductase activity in relation to $\mathrm{NO}_{3}{ }^{-}$availability in Vigna radiata (L). Wilczek. Bangladesh J. Bot. 22(1): 195-202.

Ferdous, A.K.M., Qazi A. Khaliq, M. Moynul Haque, A.J.M. Sirazul Karim and A.K.A. Bhuiyan. 2004. Effects of nitrogen fertilizer on growth, nitrogen and phosphorus uptake and yield in edible podded pea. Bangladesh Agron. J. 10(1 and 2): 135-140.

Imai, K., T. Kawano, K. Shimabe, K. Intaben and K Tanaka. 1993. Studies on dry matter production of edible canna (Canna edulisker). II. Changes of dry matter production with growth. Japan J. Crop Sci. 62: 601-608. 
Pandey, R.K, M.C Saxena, V.B. Sing.1978. Growth analysis of Blackgram genotypes. Indian J. Agric. Sci. 48(8): 466-473.

Radford, P.J. 1967. Growth analysis formulae - their use and abuse. Crop Sci. 7: 171-175.

Rashid, M.M.1995. Begun poribarer shabji. In Shabji Biggan (In Bangla.) $2^{\text {nd }}$ edition. Rashid publishing house. Dhaka. pp. 129-161.

Rao, L.J. and B.N. Mitra. 1988. Growth and yield of peanut as influenced by degree of shedding. $J$. Agron. and crop Sci. 160: 260-265.

Sushant, R., S. Dixit and G.Sing. 1999. Effect of irrigation nitrogen and phosphorus on seed yield and water use of raj-mash (Phaseolus vulgaris). Ind. J. Agron. 44(2): 382-388.

Watson, D. J. 1947. Comparative physiological study on the growth of field crops. Variation in net assimilation rate and leaf area between species and varieties and within years. Ann. Bot. N. S. 11: 41-76.

Witham, F. A., D. E. Blaydes and R. M. Devlin. 1971. Chlorophyll absorption spectrum and quantitative determination. Experiments in plant physiology. Van Nastrated. Reinhold company. New York. pp. 55-56.

(Received revised manuscript on 10 December, 2014) 